\title{
Prevalence and predictors of illicit drug use among school-going adolescents in Harare, Zimbabwe
}

\author{
Emmanuel Rudatsikira, Daniel Maposa ${ }^{1}$, Zindoga Mukandavire ${ }^{1}$, Adamson S. Muula ${ }^{2}$, \\ Seter Siziya ${ }^{3}$ \\ Departments of Global Health, Biostatistics and Epidemiology, Loma Linda University, School of Public Health, \\ Loma Linda, California, United States of America, ${ }^{1}$ Department of Applied Mathematics, National University of \\ Science and Technology, Faculty of Applied Sciences, Bulawayo, Zimbabwe, ${ }^{2}$ Department of Community Health, \\ University of Malawi, College of Medicine, Blantyre, Malawi, ${ }^{3}$ Department of Community Medicine, School of \\ Medicine, University of Zambia, Lusaka, Zambia
}

Correspondence to: Dr. Emmanuel Rudatsikira, Loma Linda University School of Public Heath, Department of Global Health, Nichol Hall Room 1318, Loma Linda, California 92350, USA. E-mail: erudatsikira@llu.edu

\begin{abstract}
Objective: To estimate the prevalence and predictors of illicit drug use among school-going adolescents in Harare, Zimbabwe.

Methods: We used data from the Global School-based Health Survey (GSHS) conducted in 2003 in Harare to obtain frequencies of a selected list of characteristics. We also carried out logistic regression to assess the association between illicit drug use and explanatory variables. For the purpose of this study, illicit drug use was defined as marijuana or glue use.

Results: A total of 1984 adolescents participated in the study. Most of the sample were females (50.7\%), 15-year-olds (30.3\%), nonsmokers and non-alcohol drinkers. Nine percent of the subjects ( $13.4 \%$ males and $4.9 \%$ females) reported having ever used marijuana or glue. Males were more likely to have used marijuana or glue than females $(\mathrm{OR}=2.70 ; 95 \% \mathrm{CI}[1.47,4.96])$. Marijuana or glue use was positively associated with cigarette smoking $(\mathrm{OR}=11.17$; $95 \% \mathrm{CI}[4.29,29.08])$, alcohol drinking (OR $=7.00 ; 95 \% \mathrm{CI}[3.39,14.47])$ and sexual intercourse $(\mathrm{OR}=5.17 ; 95 \% \mathrm{CI}$ $[2.59,10.29])$. Parental supervision was a protective factor for marijuana or glue use $(\mathrm{OR}=0.31 ; 95 \% \mathrm{CI}[0.16,0.61])$. Conclusions: Public health intervention aimed to prevent marijuana or glue use among adolescents should be designed with the understanding that illicit drug use may be associated with other behaviors such as teenage sexual activity, cigarette smoking and alcohol use.
\end{abstract}

Keywords: Adolescents, illicit drug, predictors, prevalence, use

\section{Résumé}

Objectif: Pour estimer le prévalence et prédicteurs de drogues illicites utilisent chez les adolescents de l'école-aller dans Harare, Zimbabwe.

Méthodes: Nous avons utilisé des données provenant de le Global School santé Based Survey (GSHS) menée en 2003 à Harare à obtenir des fréquences de la liste de caractéristiques. Nous avons également mené Régression logistique afin d'évaluer l'association entre la consommation de drogues illicites et variables explicatives. Aux fins de cette étude, la consommation de drogues illicites a été définie comme la marijuana ou de colle.

Résultats: 1984 adolescents ont participé dans l'étude. La plupart de l'échantillon a été femelles (50.7\%), jeunes de 15 ans (30.3\%), non-fumeurs et boissons non alcoolisées buveurs. $9 \%$ des sujets (les hommes de 13, 4\% et 4, $9 \%$ femelles) a signalé avoir jamais utilisé marijuana ou d'une colle. Les garçons étaient plus susceptibles de pour avoir utilisé marijuana ou colle que les femelles $(\mathrm{OR}=2.70 ; 95 \% \mathrm{CI}[1.47,4.96]$. Utilisation de marijuana ou d'une colle était positivement associée avec fumer des cigarettes $(\mathrm{OR}=11.17 ; 95 \%$ [4.29, 29.08], boire de l'alcool (OR = 7.00; $95 \% \mathrm{CI}[3.39 ; 14.47]$ ) et des rapports sexuels ( $\mathrm{OR}=5.17 ; 95 \% \mathrm{CI}[2.59,10.29])$. Parental surveillance a été un facteur de protection à des fins marijuana ou de colle (OR = 0, 31 inscrits aux; 95\% CI [0, 16, 0, 61]).

Conclusions: Santé publique intervention visant à empêcher la marijuana ou utilisation de colle chez les 
adolescents devrait être conçu avec la compréhension que l'usage de drogues illicites peut-être être associé à autres comportements telle activité sexuelle chez les adolescentes, tabac et d'alcool utilisation.

Mots cles: Drogues illicites, emploi, les adolescents, prévalence, les prédicteurs

DOI: $10.4103 / 1596-3519.59574$

\section{Introduction}

Page | 216

Illicit drug use among adolescents is associated with poor academic performance and may be a risk factor for cigarette smoking and unsafe sexual behaviors. ${ }^{[1-4]}$ The prevalence of health-risky behaviors associated with adolescent illicit drug use has attracted growing international recognition. Especially in southern Africa, unsafe sexual behaviors may have significantly untoward consequences, considering the high HIV prevalence estimates from the region. ${ }^{[5,6]}$ Unfortunately, adolescents and youth may underrate the harmful effects of unhealthy life styles. ${ }^{[7]}$

Previous studies among youth in Zimbabwe have reported lifetime marijuana use prevalence of between $3.4 \%$ and $12.1 \%$. We are unaware of any recent reports on the prevalence and determinants of marijuana or glue use among adolescents in Zimbabwe.

In other settings, studies have reported that marijuana has been a stepping stone towards other illicit behaviors ${ }^{[8]}$ or that co-use with other drugs is not rare. ${ }^{[9]}$

\section{Materials and Methods}

Our study involved secondary analysis of existing data available from the Harare Global School-based Health Survey (GSHS) conducted in 2003. The GSHS developed by the World Health Organization (WHO) in collaboration with United Nations' UNICEF, UNESCO and UNAIDS with technical assistance from Centers for Disease Control and Prevention (CDC) in Atlanta, USA, aims to provide data on health and social behaviors among schoolgoing adolescent students. The outcome variable was "ever used marijuana or glue." Study participants were asked the following question: During your life, how many times have you used drugs such as mbanje, dagga, marijuana or glue? Predictor variables included tobacco, cigarette and cannabis smoking; drinking alcohol; self assessment of parental supervision; having had sexual intercourse; having felt lonely or worrisome so as to disturb sleep; and gender. The questions on worry and loneliness were as follows: During the past 12 months, did you ever seriously consider attempting suicide? During the past 12 months, how often have you been so worried about something that you could not sleep at night? During the past 12 months, did you ever feel lonely and/or seriously consider committing suicide? The questionnaire was adapted and pre-tested by representatives from the Masters in Public Health program (University of Zimbabwe), Zimbabwe National Family Planning Program and the Health Promotion Unit.

The survey used a two-stage probability-sampling technique. In the first stage, a sampling frame consisted of all schools in the province containing any of the secondary school forms one to three classes. Forms one to three classes were selected because they contained the largest numbers of the target group viz., 13-15 years age group. Enrolment of each of the schools was obtained from the Ministry of Education and Culture. Schools were selected with higher probability of selection being proportional to school enrolment size, i.e., a school with a large enrolment was more likely to be selected than a school with not so large enrolment.

A self-completed questionnaire was used. Students were given instructions to answer all questions to the best of their ability but were free not to answer any question they were uncomfortable with. Data analysis was performed using SUDAAN software (Research Triangle Institute, Research Triangle Park, North Carolina, United States). SUDAAN software was preferred for its ability to handle complex study design analysis.

A weighting factor was used in the analysis to reflect the likelihood of sampling each student and to reduce bias by compensating for differing patterns of nonresponse.

We conducted logistic regression analysis to estimate associations between relevant predictor variables and lifetime marijuana or glue use. We report unadjusted odds ratios (ORs) for selected predictor variables while considering marijuana or glue use as the outcome variable. We thereafter report results for adjusted odds ratios for the factors. The school response rate was $100 \%$, and the student response rate was $84 \%$, i.e., all eligible schools participated in the study while only $84 \%$ of the eligible students eventually participated. 


\section{Results}

Table 1 presents selected characteristics of the study population of 1984 Zimbabwe adolescents. Most of the respondents were females $(50.7 \%), 15$-year-olds $(30.3 \%)$, nonsmokers $(91.5 \%)$ and non-alcohol drinkers $(90.5 \%)$. Overall, $9.1 \%$ of the participants (13.4\% males and $4.9 \%$ females) reported having used marijuana or glue.

Table 2 indicates that male subjects were more likely to use marijuana or glue than female subjects $(\mathrm{OR}=2.98$; CI $[2.10,4.22])$. Marijuana or glue use was strongly associated with cigarette smoking $(\mathrm{OR}=10.70 ; 95 \% \mathrm{CI}[6.42,17.82]$ for males and $\mathrm{OR}=12.57$; 95\% CI [6.44, 24.52] for females), alcohol drinking $(\mathrm{OR}=9.89 ; 95 \% \mathrm{CI}[5.52,16.81]$ for males and $\mathrm{OR}=13.48 ; 95 \% \mathrm{CI}[6.75,26.90]$ for females) and sexual intercourse $(\mathrm{OR}=7.03 ; 95 \%$ CI [4.08, 12.11] for males and OR $=18.71 ; 95 \%$ CI $[7.87,44.50]$ for females). Respondents who reported fighting were more likely to use marijuana or glue than those who had not engaged in fighting $(\mathrm{OR}=1.89 ; 95 \% \mathrm{CI}[1.26,2.85]$ for males and $\mathrm{OR}=3.15 ; 95 \%$ CI $[1.77,5.60]$ for females) Parental supervision was a protective factor for marijuana or glue use for both males and females $(\mathrm{OR}=0.36 ; 95 \% \mathrm{CI}[0.29,0.62]$ for males and $\mathrm{OR}=0.65 ; 95 \% \mathrm{CI}[0.39,0.95])$.
Table 3 presents results from multivariate analysis for both sexes combined as the odds ratios in bivariate analysis were in the same directions between sexes. Marijuana or glue use remained significantly associated with male gender $(\mathrm{OR}=2.70 ; 95 \% \mathrm{CI}$ $[1.47,4.96])$, cigarette smoking $(\mathrm{OR}=11.17 ; 95 \%$ CI $[4.29,29.08])$, alcohol drinking (OR $=7.00 ; 95 \%$ CI $[3.39,14.47])$ and sexual intercourse $(\mathrm{OR}=5.17$; 95\% CI [2.59, 10.29]). Parental supervision remained a protective factor for marijuana or glue use $(\mathrm{OR}=0.31 ; 95 \%$ CI $[0.16,0.61])$.

Page $\mid 217$

\section{Discussion}

The prevalence of lifetime marijuana or glue use among school-going adolescents in Harare, Zimbabwe, was 9.1\%. Males had higher prevalence (13.4\%) than females (4.9\%). Gwede et al., in 2001 reported a prevalence of ever having used marijuana or glue among forms 2 to 4 youth in school of $12.1 \%{ }^{[10]}$ This is slightly higher than the $9.1 \%$ overall prevalence estimated in our study. The difference between the prevalence in our study and that in the reports by Gwede et al., could have arisen due to the differences in ages of the study populations in the two studies. In our study, students from forms 1 to 3 were recruited, while Gwede et al., had recruited students from forms 2 to 4 . Previous studies on marijuana use in Zimbabwe have reported higher

\begin{tabular}{|c|c|c|c|}
\hline & Total \% $(n)$ & Males \% $(n)$ & Females \% ( $n)$ \\
\hline Age (years) & $100(1984)$ & $49.3(873)$ & 50.7 (1111) \\
\hline $11-13$ & $16.2(315)$ & $14.9(126)$ & 17.5 (189) \\
\hline 14 & $27.1(529)$ & $25.4(213)$ & $28.7(316)$ \\
\hline 15 & $31.1(622)$ & $31.9(282)$ & $30.3(340)$ \\
\hline $16-17$ & $25.6(518)$ & $27.8(252)$ & $23.5(266)$ \\
\hline \multicolumn{4}{|l|}{ Worry } \\
\hline No & $87.0(1731)$ & $88.0(764)$ & $85.9(956)$ \\
\hline Yes & $13.1(260)$ & $12.0(105)$ & $14.1(153)$ \\
\hline \multicolumn{4}{|l|}{ Loneliness } \\
\hline No & $89.8(1774)$ & $90.6(776)$ & $89.4(990)$ \\
\hline Yes & $10.2(208)$ & $9.4(84)$ & $10.6(119)$ \\
\hline \multicolumn{4}{|c|}{ Cigarette smoking } \\
\hline No & $91.5(1817)$ & 89.7 (769) & $93.6(1039)$ \\
\hline Yes & $8.5(157)$ & $10.4(88)$ & $6.4(65)$ \\
\hline \multicolumn{4}{|c|}{ Drinking alcohol } \\
\hline No & $90.5(1617)$ & $89.7(688)$ & 91.4 (921) \\
\hline Yes & 9.5 (170) & $10.3(82)$ & $8.6(86)$ \\
\hline \multicolumn{4}{|c|}{ Sexual intercourse } \\
\hline No & $88.0(1280)$ & $80.2(479)$ & $94.7(796)$ \\
\hline Yes & $12.0(161)$ & $19.8(113)$ & $5.3(45)$ \\
\hline \multicolumn{4}{|l|}{ Fighting } \\
\hline No & $64.8(1303)$ & $58.8(511)$ & 70.7 (792) \\
\hline Yes & $35.2(679)$ & $41.2(360)$ & $29.3(319)$ \\
\hline \multicolumn{4}{|c|}{ Parental supervision } \\
\hline Yes & $54.9(1043)$ & $56.9(471)$ & $47.4(507)$ \\
\hline No & $45.1(850)$ & $43.1(341)$ & $52.6(564)$ \\
\hline \multicolumn{4}{|c|}{ Marijuana use } \\
\hline No & 90.9 (1801) & $86.6(739)$ & $95.1(1051)$ \\
\hline Yes & $9.1(170)$ & $13.4(115)$ & $4.9(53)$ \\
\hline
\end{tabular}




\begin{tabular}{|c|c|c|c|}
\hline & Total & Males & Females \\
\hline \multicolumn{4}{|l|}{ Age (years) } \\
\hline $11-13$ & 1.00 & 1.00 & 1.00 \\
\hline 14 & $0.60[0.34,1.07]$ & $0.61[0.29,1.30]$ & $0.55[0.24,1.30]$ \\
\hline 15 & $1.16[0.71,1.91]$ & $1.36[0.71,2.60]$ & $0.57[0.25,1.32]$ \\
\hline $16-17$ & $1.49[0.90,2.45]$ & $1.41[0.73,2.72]$ & $1.34[0.61,2.90]$ \\
\hline \multicolumn{4}{|l|}{ Gender } \\
\hline Females & 1.00 & - & - \\
\hline Males & $2.98[2.10,4.22]$ & - & - \\
\hline \multicolumn{4}{|c|}{ Cigarette smoking } \\
\hline No & 1.00 & 1.00 & 1.00 \\
\hline Yes & $11.83[7.98,17.53]$ & $10.70[6.42,17.82]$ & $12.57[6.44,24.52]$ \\
\hline \multicolumn{4}{|c|}{ Drinking alcohol } \\
\hline No & 1.00 & 1.00 & 1.00 \\
\hline Yes & $\begin{array}{c}10.56 \\
{[7.05,15.80]}\end{array}$ & $9.89[5.52,16.81]$ & $13.48[6.75,26.90]$ \\
\hline \multicolumn{4}{|l|}{ Fighting } \\
\hline No & 1.00 & 1.00 & 1.00 \\
\hline Yes & $2.49[1.79,3.46]$ & $1.89[1.26,2.85]$ & $3.15[1.77,5.60]$ \\
\hline \multicolumn{4}{|c|}{ Sexual intercourse } \\
\hline No & 1.00 & 1.00 & 1.00 \\
\hline Yes & $\begin{array}{c}11.53 \\
{[7.28,18.25]}\end{array}$ & $7.03[4.08,12.11]$ & $18.71[7.87,44.50]$ \\
\hline \multicolumn{4}{|c|}{ Parental supervision } \\
\hline No & 1.00 & 1.00 & 1.00 \\
\hline No & $0.42[0.29,0.62]$ & $0.36[0.22,0.58]$ & $0.65[0.39,0.95]$ \\
\hline
\end{tabular}

\begin{tabular}{|c|c|}
\hline \multicolumn{2}{|c|}{$\begin{array}{l}\text { Table 3: Adjusted }{ }^{*} \text { odds ratios with } 95 \% \\
\text { confidence interval for marijuana use by age, } \\
\text { gender, parental supervision, smoking, drinking } \\
\text { alcohol, physical fighting, injury and having sex } \\
\text { among adolescents in Zimbabwe }\end{array}$} \\
\hline Variable & Odds ratios with $95 \% \mathrm{Cl}$ \\
\hline \multicolumn{2}{|l|}{ Age (years) } \\
\hline $11-13$ & 1.00 \\
\hline 14 & $1.41[0.45,4.44]$ \\
\hline 15 & $2.50[0.82,7.63]$ \\
\hline $16-17$ & $1.50[0.49,4.61]$ \\
\hline \multicolumn{2}{|l|}{ Gender } \\
\hline Females & 1.00 \\
\hline Males & $2.70[1.47,4.96]$ \\
\hline \multicolumn{2}{|c|}{ Sexual intercourse } \\
\hline No & 1.00 \\
\hline Yes & $5.17 ;[2.59,10.29]$ \\
\hline \multicolumn{2}{|l|}{ Fighting } \\
\hline No & 1.00 \\
\hline Yes & $1.12[0.38,3.31]$ \\
\hline \multicolumn{2}{|c|}{ Drinking alcohol } \\
\hline No & 1.00 \\
\hline Yes & $7.00[3.39,14.47]$ \\
\hline \multicolumn{2}{|c|}{ Cigarette smoking } \\
\hline No & 1.00 \\
\hline Yes & $11.17[4.29,29.08]$ \\
\hline \multicolumn{2}{|c|}{ Parental supervision } \\
\hline No & 1.00 \\
\hline Yes & $3.20[1.63,6.28]$ \\
\hline
\end{tabular}

prevalence of its use among males compared to females. ${ }^{[11,12]}$ This male predominance has also been reported in South Africa. ${ }^{[13]}$
Global data from the 1990s have shown that marijuana is the most widely used illicit drug in the world. ${ }^{[14]}$ Marked increases have been observed in the 1990s in the percentages of youth in the United States who reported using marijuana. High prevalence of marijuana use has been reported in Kenya, Zimbabwe, Nigeria ${ }^{[11,12,14-17]}$ and many other settings outside of Africa. ${ }^{[18-20]}$

We also found that prevalence of current use of cigarettes was 8.5\%; alcohol, 9.5\%; and sexual intercourse, $12.0 \%$. The prevalence of current use of cigarettes among adolescents in Harare in 2003 $(8.5 \%)$ was much lower than the $18 \%$ reported among individuals in a similar age group in 1999 in the Global Youth Tobacco Survey. ${ }^{[21]}$ We are unaware of the reasons behind these changes, but we suggest that the changing socioeconomic environment in the country may be a contributing factor.

The associations between various behaviors like alcohol use, violent behaviors, experience of sexual intercourse and illicit drug use have been described previously. ${ }^{[2,23]}$ The clustering of unhealthy behaviors among adolescents clearly suggests that efforts aimed at controlling or preventing one specific problematic behavior must be designed to deal with multiple behaviors at the same time. ${ }^{[24]}$

Not surprisingly also, adolescents who reported lack of parental supervision were more likely to have 
used marijuana or glue than those who reported presence of parental supervision. Best et al., have reported that adolescents who spent less time with parents but spent more time with peers were more likely to abuse illicit drugs. ${ }^{[25]}$ The role of parental supervision, therefore, cannot be overemphasized.

Our study has several limitations. We used data that were self-completed by the study participants. Study participants may have misreported their marijuana or glue use despite assurances of confidentiality. Most of the literature on the reliability of self-reports on sensitive topics has come from developed nations. ${ }^{[26-28]}$ While some reports suggest acceptable reliability, others present lower scores. We do not know how far these reports from developed nations are applicable to a developing nation such as Zimbabwe. In addition, the study was limited to adolescents available in school on the day of the survey. To the extent that adolescents in school may be different from the out-of-school adolescents, our findings may not be representative of all adolescents in Harare. Finally, the question which was asked was, during your life, how many times have you used drugs such as mbanje, dagga, marijuana or glue? This would suggest that students who used either marijuana or glue could have answered in the affirmative. Similarly, students who used both drugs may have answered in the affirmative.

\section{Conclusion}

Marijuana or glue use by adolescents in Harare is associated with male gender, sexual activity, alcohol use, current cigarette smoking and parental supervision. The planning, implementation and evaluation of public health intervention should take into consideration this clustering of factors.

\section{Acknowledgments}

We thank the students who participated in the Zimbabwe Global School-based Survey; and their parents for granting permission for their children's participation in the survey. Special thanks to Dr. EGV Sithole, who coordinated the data-collection exercise.

\section{References}

1. Kliewer W, Murrelle L. Risk and protective factors for adolescent substance use: Findings from a study in selected central American countries. ] Adolesc Health 2007;40:448-55.

2. Edwards JM, Irritani B], Hallfors DD. Prevalence and correlates of exchanging sex for drugs or money among adolescents in the United States. Sex Transm Infect 2006;82:354-8.

3. Lee LK, Chen PC, Lee KK, Kaur ]. Premarital sexual intercourse among adolescents in Malaysia: A crosssectional Malaysian school survey. Singapore Med ]
2006;47:476-81.

4. Morojele NK, Brook JK, Kachieng'a MA. Perceptions of sexual risk behaviours and substance abuse among adolescents in South Africa: A qualitative investigation. AIDS Care 2006;18:215-9.

5. Gavin L, Galavotti C, Dube H, McNaghten AD, Murwirwa M, Khan R, et al. Factors associated with HIV infection in adolscents in females in Zimbabwe. J Adolesc Health 2006;39:596.e11-8.

6. Ferrand RA, Luethy R, Bwakura F, Mujuru H, Miller RF, Corbett EL. HIV infection presenting in older children and adolescents: A case series study from Harare, Zimbabwe. Clin Infect Dis 2007;44:874-8.

7. McMaster ], Keshav C. Perceptions of normal alcohol use held by Zimbabwean high school students. Cent Afr J Med 1994;40:88094.

8. Greene B]. Sequential use of drugs and alcohol: A reexamination of the stepping-stone hypothesis. Am J Drug Alcohol Abuse 1980;7:83-99.

9. Tsuang MT, Lyons M], Meyer JM, Doyle T, Eisen SA, Goldberg], et al. Co-occurrence of abuse of different drugs in men:The drug-specific and shared vulnerabilities. Arch Gen Psychiatry 1998;55:967-72.

10. Gwede CK, McDermott R], Weshoff WW, Mushore M, Mushore T, Chitsika E, et al. HIV risk behaviour of rural secondary school students in Zimbabwe. Health Educ Behav 2001;28:608-23.

11. Eide AH, Acuda WS. Drug use among secondary school students in Zimbabwe. Addiction 1995;90:1517-27.

12. Khan N, Arnott R. Substance use among rural secondary schools in Zimbabwe: Patterns and prevalence. Cent Afr ] Med 1996;42:223-9.

13. Taiwo T, Goldstein S. Drug use and its association with deviant behaviour among rural adolescent students in South Africa. East Afr Med ] 2006;83:500-6.

14. Kingery PM, Alford AA, Goggeshall MB. Marijuana use among youth: Epidemiologic evidence from the US and other nations. Sch Psychol Int 1999;20:9-21.

15. Adelekan ML. Self-reported drug use among secondary school students in the Nigerian State of Ogun. Bull Narc 1989;41:109-16.

16. Adelekan ML, Ndom RJ. Trends in prevalence and pattern of substance use among secondary school Pupils in Ilorin, Nigeria. West Afr ] Med 1997;16:157-64.

17. Pela OS. Patterns of adolescent psychoactive substance use and abuse in Benin City, Nigeria. Adolescence 1989;24:569-74.

18. Miller PM, Plant M. Drinking, smoking, and illicit drug use among 15 and 16 year olds in the United Kingdom. BM] 1996;313:394-7.

19. McAllister I, MakkaiT. Whatever happened to Marijuana? Patterns of Marijuana use in Australia, 1985-1988. Int ] Addict 1991;26:491-504.

20. Pedersen JM. Substance abuse among greenlandic school children. Arctic Med Res 1992;51:67-71.

21. Global Youth Tobacco Survey Collaborative Group. Tobacco use among youth: A cross country comparison. Tob Control 2002;11:252-70.

22. Palen LA, Smith EA, Flisher A], Caldwell LL, Mpofu E. Substance use and sexual risk behaviour among South African eighth grade students. ] Adolesc Health 2006;39:761-3.

23. Liu A, Kilmarx P, Jenkin RA, Manopaiboon C, Mock PA, Jeeyapunt $\mathrm{S}$, et al. Sexual initiation, substance use and sexual behaviour and knowledge among vocational students in northern Thailand. Int Fam Plan Perspect 2006;32:126-35.

24. Grant JD, Schererrer JF, Lynskey MT, Lyons M], Eisen JA, Tsuang MT, et al. Adolescent alcohol use is a risk factor for adult alcohol and drug dependence: Evidence from 
a twin design. Psychol Med 2006;36:109-18.

25. Best D, Gross S, Manning V, Gossop M, Witton ], Strang ]. Cannabis use in adolescents: The impact of risk and protective factors and social functioning. Drug Alcohol Rev 2005;24:483-8.

26. Linlonen T, Ahlstrom S, Metso L. The reliability of self-reported drinking in adolescence. Alcohol Alcohol 2004;39:362-8.
27. Levy S, Sherritt L, Harris SK, Gates EC, Holder DW, Kulig JN, et al. Test-retest reliability of adolescents' self-report of substance use. Alcohol Clin Exp Res 2004;28:1236-41.

28. Riley AW. Evidence that school-age children can selfreport on their health. Ambul Pediatr 2004;4:371-6.

Source of Support: Nil, Conflict of Interest: None declared. 